\title{
Sources of normativity in childhood depression
}

\author{
Argyris Stringaris ${ }^{1}$
}

Published online: 23 October 2021

This is a U.S. government work and not under copyright protection in the U.S.; foreign copyright protection may apply 2021

Measuring depression outcomes means making normative judgements, that is, deciding what is good or better than before, and what is bad or what may have gotten worse. It doesn't matter if one uses a scale to measure depression or if one is simply using their clinical impression to guide them.

But how do we know what is good and what is bad and whether any change is for the better? Also, how do we know what to ask, whom to ask and how to ask about such outcomes?

In their important study, Krause et al. [1] did something rather unusual for our field: they asked participants of a depression psychotherapy trial about what they think had changed due to the intervention; they also asked the participant's parents and their therapists. The psychotherapy trial was the heroic IMPACT [2] and the data in the Krause paper come from IMPACT-ME, the qualitative study nested in the bigger one. Famously, IMPACT showed no effectiveness differences between three arms: a Brief Psychosocial Intervention, Cognitive Behavioural Therapy, and ShortTerm Psychoanalytic Psychotherapy.

Krause et al.'s approach is unusual because in depression trials we, the researchers, the ones who design the measurement scales and trials, are usually our own source of normativity. A typical depression scale is designed by asking experts what they believe are the items (questions) that capture the most important features of adolescent depression. A big pool of questions is created, out of which, through statistical item-reduction techniques, a final instrument (i.e. questionnaire or interview) is generated [3]. This is then handed to the patients themselves or to clinicians who interview patients and that's how depression is measured. Alternatively, clinicians assessing the patients are asked to form a "global impression" of the adolescent and provide a rating about whether they have changed.

Argyris Stringaris

argyris.stringaris@nih.gov

1 Section of Clinical and Computational Psychiatry, National Institute of Mental Health, National Institutes of Health, Bethesda, MD, USA
Krause et al. show that over $90 \%$ of trials only collect information in this way and ask primarily about depressive symptoms-a sort of DSM symptom count. But are the things that we have been asking about the things that matter to adolescents, their parents or their therapists? As Chevance et al. have shown previously in adults [4], Krause also demonstrates for this age group: only to an extent. Whilst all three-adolescents, parents and therapists—often care about mood symptoms, they also care about a host of other things, such as family relationships, skills, everyday functioning, that are rarely considered in the measures that define the outcomes of depression trials.

Krause et al.'s study questions our conceptions of normativity. Consider the following scenarios: "I do not feel that low any more, I got better but I still do not function properly, feel like I cannot concentrate"; or the converse, "at last I get on better with my family, but my mood has improved only a little". Who has improved more?

But many will ask, why should we care? Surely, if we only had a marker of depression as, say oncology has for tumours, all this discussion might prove to be simple academic indulgence.

This view is based on at least two misconceptions.

For one, such an argument on biomarkers is based on the problematic notion that science or technology are in and of themselves a source for normative judgements. It should be evident that science and its tools do not carry or generate themselves normative values, this comes from the people and the societies using the tools. It has even been cogently argued that scientific knowledge itself can only be produced because it is based on existing personal and societal constructs of normativity, of what is right vs wrong, correct vs incorrect, useful vs non-useful [5]. It is the job of good science to be transparent about such sources of normativity and their implications for practice.

Also, such dreams that biomarkers will deliver us from the responsibility of addressing these questions ignores what happens in the rest of medicine. My father's treating haematologists were tracking the mRNA expression of his NPM1 gene mutation when they were treating his leukaemia; but 
they also listened to my father and to us, when we told them that he did not wish to have another course of ghastly chemotherapy. He preferred to see his grandchildren, be able to eat again, and take his chances with a (then) still experimental drug over another gruelling round of chemo (and his decision proved the right one in this case). Similarly, a sensible surgeon would not operate on the hip of an elderly person, simply by looking at the fracture on the X-ray-a host of other personal and social factors enter their judgement, what would be better and what worse for that particular person. It could be argued that the goodness of any marker in medicine is judged against its ability to predict not just a narrow trial target, but outcomes that really matter to the individual and society, such as being able to function as one did before or at a level that seems reasonable (the types of outcomes reported in the Krause trial).

The Krause et al. article should therefore be seen for the field as a call for action - perhaps for something harder, a call for re-thinking how we do things. Here are some ideas about how we might do this.

First, the Krause paper makes clear that we should do a lot more to capture what matters to stakeholders. Krause et al. show a neat way to do this using qualitative methodology. This can form the basis for developing new quantitative instruments or repurposing existing measures that can evaluate, for example, impairment [6]. How best to do all this will be a question that mixed methods and quantitative scientists will have to grapple with. Critics are bound to ask how representative qualitative accounts are (in the Krause et al. paper, data from only those, on whom information from the whole triad was collected, was analysed). Quantitative scientists will also want to know how issues of solipsism would be avoided: ultimately, what is the criterion for grouping together people's opinions, how is the shared parsed from the unique and what should be done with unique, person-specific information (and how is it separated from mere error/noise)?

Second, the paper by Krause suggests we should do more to understand how relationships are impacted upon by depression and how they, in turn, influence the outcome of depression. The importance of the family for a child's wellbeing is well established (and the role of parenting interventions, for example, well known for certain disorders), yet data about family relationships are rarely collected. And with some notable exceptions [7] very few depression trials address family issues.

Third, it was interesting to see that mood and affect is seen as important by so many young people, parents and therapists in the Krause et al. paper. But one must not forget that mood remains a scientifically nebulous construct. Recent computational approaches try to build a basic science of mood and affect [8], but there is a lot more to accomplish-including the understanding of issues such as counter-hedonic [9] motivation particularly in adolescents and the potential adaptiveness of negative moods in certain environments, amongst other things. Our current normativity in psychiatry views negative moods as inherently unhealthy (as exemplified in how scales are used: you are considered worse the more negative affect you report, starting from zero).

Fourth, often the results of qualitative studies are seen as antithetical to quantitative and technological approaches. They need not be. One can easily see how technology could be used in the form of natural language processing on large datasets (e.g. free texts of people with depression who attend clinics, or of practitioners) to capture people's views and group them. One can also see how clinical tool development may benefit from considering more multivariate assessment and monitoring tools, ones that capture many of the domains that are mentioned in the Krause paper.

The Krause et al. paper is timely one could argue that we should have had the benefits of seeing its results much earlier. Many will be tempted to develop guides about what information should be collected-and there is certainly value in this. But there is vast potential ahead for top quality and useful science that will help us understand how and what people report and how it matters for their health and that of their families. It is a much-needed form of basic clinical neuroscience.

\section{References}

1. Krause K, Midgley N, Edbrooke-Childs J, Wolpert M (2020) A comprehensive mapping of outcomes following psychotherapy for adolescent depression: the perspectives of young people, their parents and therapists. Eur Child Adolesc Psychiatry. https://doi. org/10.1007/s00787-020-01648-8

2. Goodyer IM, Reynolds S, Barrett B et al (2017) Cognitive-behavioural therapy and short-term psychoanalytic psychotherapy versus brief psychosocial intervention in adolescents with unipolar major depression (IMPACT): a multicentre, pragmatic, observerblind, randomised controlled trial. Health Technol Assess 21:194. https://doi.org/10.3310/hta21120

3. Streiner DL, Norman GR, Cairney J (2015) Health measurement scales: A practical guide to their development and use, 5th edn. Oxford University Press, New York, NY https://doi.org/10.1093/ med/9780199685219.001.0001

4. Chevance A, Ravaud P, Tomlinson A et al (2020) Identifying outcomes for depression that matter to patients, informal caregivers, and health-care professionals: qualitative content analysis of a large international online survey. The Lancet Psychiatry 7:692702. https://doi.org/10.1016/S2215-0366(20)30191-7

5. Peter Janich, Was ist Erkenntniss: Eine Philosophische Einführung, CH Beck Verlag, München 2000 (BsR 1376), ISBN 3-406-45916-1

6. Stringaris A, Goodman R (2013) The value of measuring impact alongside symptoms in children and adolescents: a longitudinal assessment in a community sample. J Abnorm Child Psychol 41:1109-1120. https://doi.org/10.1007/s10802-013-9744-x 
7. Luby JL, Barch DM, Whalen D et al (2018) A randomized controlled trial of parent-child psychotherapy targeting emotion development for early childhood depression. Am J Psychiatry 175: 1102-1110. https://doi.org/10.1176/appi.ajp.2018.18030321

8. Keren H, Zheng C, Jangraw DC et al (2021) The temporal representation of experience in subjective mood. eLife 10:1-24. https:// doi.org/10.7554/eLife.62051

9. Riediger M, Schmiedek F, Wagner GG, Lindenberger U (2009) Seeking pleasure and seeking pain: differences in prohedonic and contra-hedonic motivation from adolescence to old age. Psychol Sci 20:1529-1535. https://doi.org/10.1111/j.1467-9280.2009. 02473.x 